SIX YEARS' EXPERIENCE WITH COMBINATION CHEMOTHERAPY FOR MALIGNANT TUMOURS OF THE NEUROAXIS

WOLFF KIRSCH (Denver) described the treatment of glioblastoma multiforme with Warfarin, and showed a film of tissue cultures.

TRAUMA TRIGGERED MIGRAINE AND JUVENILE HEAD TRAUMA SYNDROMES

DAVID HAAS, GERGORIO S. PINEDA, and HERBERT LOURIE (Syracuse) described the clinical spectrum of trauma triggered migraine derived from an analysis of 50 attacks in 25 patients. The attacks were placed in four clinical types: (1) hemiparesis, (2) somnolence, irritability, and vomiting, (3) blindness, (4) brain-stem signs.

All attacks followed mild head trauma after a latent interval lasting generally between one and 10 minutes. Forty of the 50 attacks occurred in patients under 14 years of age. Full recovery occurred after a variable time in all but one case. This patient and one other had angiographically demonstrable occlusion of a branch of a middle cerebral artery. In its clinical and laboratory features trauma triggered migraine is similar to spontaneous migraine. It is a common phenomenon after head trauma in children.

SURGERY OF CRANIOFACIAL DEFORMITIES J. A. JANE (Charlottesville) noted that until about 10 years ago the outlook for rehabilitation of a child with major craniofacial deformity involving malposition of the eyes and significant asymmetry of facial and cranial bones was dismal. Although multiple attempts were often made by plastic surgeons to improve the symmetry of the features, the malposition of the skeleton, especially in the orbital region, made the final result disappointing to the patients' families and surgeons. In the field of neurosurgery attention had been directed towards prematurely fused suture lines, and efforts had been made to provide room for brain enlargement. Serious secondary deformities of the skull and face had been seen in many children during the years of growth after apparently successful maintenance of brain function. With further experience there had been a tendency towards operating at a progressively earlier age. The advantages of earlier treatment of these anomalies were the avoidance of psychological trauma to patients and parents and the possibility of more normal growth and the achievement of functions such as binocular fusion. In a series of over 20 cases operated on under the age of 6 years there had been one operative death. The patients included examples of Crouzon's disease, encephalocoeles, and complex craniofacial anomalies.

\section{DISSECTING ANEURYSMS OF THE INTERNAL CAROTID ARTERY}

J. W. CORRELl, E. H. WOOD, and M. B. CAMINS (New York) described two patients with dissecting aneurysms of the internal carotid artery. In both there had been repeated episodes of cerebral embolism. The arteriographic findings in the two cases were markedly dissimilar. Both patients had been treated surgically and both recovered. One had a resection of the lesion followed by end to end anastomosis of the internal carotid artery, and the other underwent ligation of the internal carotid artery to prevent further embolism.

\section{SURGICAL REPAIR OF HIGH CERVICAL CAROTID ARTERY ANEURYSMS}

H. MORGAN and J. T. ROBERTSON (Memphis) drew attention to the difficulty of treating high cervical carotid artery aneurysms just below the base of the skull. They reviewed three cases demonstrating such lesions and detailed their surgical approach. The first case was a false aneurysm of the internal carotid artery after a gun shot wound at a level between the atlas and axis. In the second case a dissecting aneurysm of the internal carotid artery extending from the carotid bifurcation to the base of the skull was repaired. In the third patient a large aneurysmal formation of the distal part of the internal maxillary artery, together with an associated arteriovenous fistula, were resected. With careful sharp dissection access to the base of the skull could safely be gained anterolaterally above the styloid process. Mobilization of the superficial part of the parotid gland was required and care must be exercised to avoid injuring the neighbouring cranial nerves.

\section{MATHEMATICAL MODEL OF CEREBROSPINAL FLUID DYNAMICS}

A. TAlAllA and R. BLOCK (Hamilton) described a three chamber model of the dynamics of CSF flow. Secretion and absorption of CSF, flow resistance, vascular pulsations, and viscoelastic properties of a spherical shell brain were among the parameters considered. Conditions were shown to exist where, without interruption of flow, hydrocephalus develops.

CHRONIC MEASUREMENT OF EPIDURAL PRESSURE WITH AN INDUCTION POWERED OSCILLATOR TRANSDUCER H. GRADY RYLANDER, H. LYNDON TAYLOR, JOHN P. WISSINGER, and JIM L. STORY (San Antonio) had designed an induction powered oscillator transducer for the chronic measurement of epidural pressure. The IPOT combined the durability and long life of the passive resonant circuit type transducers with the sensitivity and telemetry capabilities of battery 